\title{
Transatlantica
}

Revue d'études américaines. American Studies Journal

\section{Christine Raguet-Bouvart. Vladimir Nabokov.}

Paris : Belin, 2001. 128 p. http://www.editions-belin.com.

\section{Yona Dureau}

\section{(2) OpenEdition}

Journals

Édition électronique

URL : http://journals.openedition.org/transatlantica/720

DOI : 10.4000/transatlantica.720

ISSN : $1765-2766$

Éditeur

AFEA

\section{Référence électronique}

Yona Dureau, « Christine Raguet-Bouvart. Vladimir Nabokov. », Transatlantica [En ligne], 1 | 2003, mis en ligne le 05 avril 2006, consulté le 29 avril 2021. URL : http://journals.openedition.org/transatlantica/ 720 ; DOI : https://doi.org/10.4000/transatlantica.720

Ce document a été généré automatiquement le 29 avril 2021.

\section{(c) (†) $\ominus$}

Transatlantica - Revue d'études américaines est mis à disposition selon les termes de la licence Creative Commons Attribution - Pas d'Utilisation Commerciale - Pas de Modification 4.0 International. 


\section{Christine Raguet-Bouvart. Vladimir Nabokov.}

Paris : Belin, 2001. 128 p. http://www.editions-belin.com.

\section{Yona Dureau}

1 L'ouvrage de Christine Raguet-Bouvart sur Vladimir Nabokov se présente comme une étude concise et érudite de l'oeuvre et de la vie du grand écrivain russe. L'ouvrage tient en 119 pages de texte, suivies d'une chronologie biographique de trois pages et d'une bibliographie sélective. Cette critique, publiée dans la fameuse série «voix américaines ", se révèle indispensable, aussi bien pour l'étudiant cherchant à se familiariser avec cette oeuvre encore inconnue pour lui, que pour le chercheur en quête d'informations ponctuelles, classées de façon rigoureuse et précise. Toutefois, le travail de Christine Raguet-Bouvart ne se limite pas à une synthèse d'informations. Il apporte avec clarté de nouvelles perspectives critiques, démontrant le jeu complexe inter-linguistique et intertextuel établi par Nabokov au sein de ses romans, guidant le lecteur au sein d'un dédale de références artistiques, transmettant avec conviction l'essence de l'esthétique du grand maître en littérature, et insufflant l'intuition devant inspirer le lecteur dans une perception polysémique de ses romans. Les citations des oeuvres, bien que données dans la langue de Molière, sont choisies avec subtilité, rendant compte $\mathrm{du}$ travail littéraire de l'auteur en anglais, voire en russe

Ainsi, l'ouvrage de Christine Raguet-Bouvart s'avère incontournable, indispensable à tous ceux que l'oeuvre de Nabokov attire, intrigue, ou désarme. 
INDEX

Thèmes : Recensions

\section{AUTEUR}

YONA DUREAU

Université Jean-Monnet - Saint-Etienne 